\title{
LAND USE AND LAND COVER CHANGE IN CHINA'S LOESS PLATEAU: THE IMPACTS OF CLIMATE CHANGE, URBAN EXPANSION AND GRAIN FOR GREEN PROJECT IMPLEMENTATION
}

\author{
WANG, T. $^{12^{*}}-$ YANG, M. H. $^{1}$ \\ ${ }^{1}$ College of Geomatics, Xi'an University of Science and Technology \\ 58 Yanta Road, Xi'an, Shaanxi, P. R. China \\ (phone: +86-29-8912-7648; fax: +86-29-8558-3176)
}

${ }^{2}$ State Key Laboratory of Soil Erosion and Dryland Farming on the Loess Plateau, Institute of Water and Soil Conservation, Chinese Academy of Sciences and Ministry of Water Resources

26 Xinong Road, Yangling, Shaanxi, P. R. China

(phone: +86-29-8701-2411; fax: +86-29-8701-2210)

*Corresponding author

e-mail:wht432@xust.edu.cn; phone:+86-29-8912-7648; fax:+86-29-8558-3176

(Received $1^{\text {st }}$ Apr 2018; accepted $12^{\text {th }}$ Jun 2018)

\begin{abstract}
This paper used data on land use, normalized difference vegetation index, digital elevation model, temperature and precipitation, and urban distribution to analyse the impacts of climate change, urban expansion and the Grain for Green project implementation on land use and land cover change in the Loess Plateau between 1980 and 2015 based on a single factor and comprehensive factor analysis. The aim of this paper is to explore the spatial expression of human activities under the influence of urban expansion, climate change, and the implementation of the Grain for Green project. The results indicated that climate change dominated among the influencing factors of land use and land cover change in the Loess Plateau, accounting for $93.65 \%$ of the total, with a surface-like distribution. It was followed by urban expansion, accounting for $5.46 \%$ of the total, with a point-like distribution. The impact of the Grain for Green project implementation accounted for $0.64 \%$, with a patchy distribution. However, due to the low resolution, the quantitative assessment results regarding the role of the Grain for Green project implementation was lower, while for climate change and urban expansion, results were higher.
\end{abstract}

Keywords: NDVI, temperature, precipitation, correlation coefficient, buffer analysis

\section{Introduction}

Land use and land cover change (LUCC) is an important component of global environmental change research and was one of the core programs for the International Geosphere-Biosphere Programme (IGBP) and International Human Dimensions Programme (IHDP) joint research between 1994 to 2005 (Liu et al., 2010). The Global land project (GLP) replaced the LUCC research program and became the global land system research program during 2005-2015. It inherited the content of the LUCC program and now focuses more on land system dynamics, change results and integrated sustainability analysis and simulation (Milne et al., 2009). Through preliminary LUCC studies, scholars have confirmed the role of LUCC in the earth surface system, and LUCC has become important data and background information for any land-related research (Liu et al., 2014a).

The main influencing factors of the LUCC process are climatic factors and human activities. Climatic factors affect LUCC process mainly through the influence of land surface vegetation, and human activities mainly impact LUCC by affecting land use on 
the earth's surface (Chen et al., 2014; Song et al., 2014). In terms of climatic factors, arid and semi-arid regions, ecologically fragile and sensitive areas are affected by climate change and dramatic changes in LUCC (Guan et al., 2015; Li et al., 2015a; Lu et al., 2016), especially with changes in precipitation and increases in temperature that increase the amount of glacial meltwater, which leads to greater water volume and improved vegetation growth conditions. These changes would promote the development of regional LUCC in a more sustainable direction, which is conducive to improved regional ecological and environmental conditions (Niu et al., 2013; Wang and Wang, 2013; Liu et al., 2014b). Human activities include agricultural reclamation, urban expansion, ecological construction and the implementation of environmental protection policies. The primary tropical rainforest areas in the world face degradation of surface vegetation caused by agricultural reclamation. Tropical rainforests and ecosystems have been severely damaged by this, which has had a serious negative effect on global environmental change (Malhi et al., 2014; Chen et al., 2016). In the arid region of northwestern China, Xinjiang also faces a large amount of land reclamation. Despite the increase in the amount of water in the region caused by global warming, reclamation of and extraction of surface water and groundwater in large quantities require the supervision and scientific management of government departments, in order to prevent terrestrial salinization and water scarcity caused by over-consumption (Feng et al., 2016; Wei et al., 2017). In terms of urban expansion, in countries that have experienced centuries of industrialization such as Europe and the United States, the pace of urban expansion has been effectively kept in check and even halted (Theobald, 2005; Seto et al., 2012). In the emerging economies of the world, such as China with its rapid economic development, the process of urbanization is accelerating, orderly and disorderly urban expansion has had a significant impact on the earth's surface and LUCC. Various types of land use and land cover in the area around the city are gradually replaced by urban lands, which leads to the simplification and homogenization of LUCC structure and the gradual loss of spatial heterogeneity in specific areas (Li et al., 2013; Chuai et al., 2015; Wang et al., 2016). With regard to the implementation of the government's ecological construction and protection policies, China has made a great deal of effort. It has successively implemented the construction of the "Three Norths" shelterbelt, closing hillsides for afforestation and prohibiting grazing activities, as well as the implementing the Grain for Green project (GGP) to restore farmlands to forest land and grassland (Li et al., 2015b; Jiang et al., 2016; Li et al., 2016). The GGP has a wide scope of work, a large resident population, significant funds and positive environmental impacts. The vegetation on the land surface has been restored and improved, and the vegetation coverage has continuously increased (Deng et al., 2014; Liu et al., 2017). The first round of GGP was started in 2000 and completed in 2008, and the second round was implemented in 2015. Through subsidies, the implementation of GGP has promoted farmers to voluntarily give up the cultivation of farmland in steeper regions.

The Loess Plateau is a major environmentally fragile and sensitive area in China and also a hotspot for research. The impacts of climate change, urban expansion and the implementation of the GGP on LUCC are well known in the region ( $\mathrm{Su}$ and $\mathrm{Fu}, 2013$; Chen et al., 2015; Xie et al., 2016). However, most studies have focused on one or two factors, while the quantitative study of three factors has not been done. This paper analyzes and quantitatively evaluates the impacts of climate change, urban expansion and the implementation of the GGP on LUCC in the Loess Plateau, using data on land 
use, normalized difference vegetation index (NDVI), digital elevation model (DEM), temperature, precipitation and urban distribution from 1980 to 2015. It provides scientific support for the protection and utilization of the environmental resources of the Loess Plateau.

\section{Materials and methods}

\section{Study area}

The Loess Plateau is located in the centre and western region of China, east of the Taihang Mountains, west Wuqiaoling Mountains and Riyue Mountains, and south of the Qinling Mountains, north of the Great Wall. The geographical coordinates are $100^{\circ} 50^{\prime}-$ $114^{\circ} 12^{\prime} \mathrm{E}$ and $33^{\circ} 40^{\prime}-41^{\circ} 18^{\prime} \mathrm{N}$, and it encompasses the provinces or autonomous regions of Qinghai, Gansu, Ningxiang, Inner Mongolia, Shaanxi, Shanxi and Henan, with a total area of $63.2 \times 104 \mathrm{~km}^{2}$. The area mainly has a temperate continental monsoon climate, with cold and dry winters and hot and rainy summers. The average annual precipitation is about $460 \mathrm{~mm}$, which decreases in a southeast-northwest direction. The southeast is a semi-humid zone, the middle is a semi-arid zone, and the northwest is an arid zone. The Loess Plateau is between $85-5210 \mathrm{~m}$ above sea level, rising from east to west and is the largest loess accumulation area in the world (Fig. 1a).

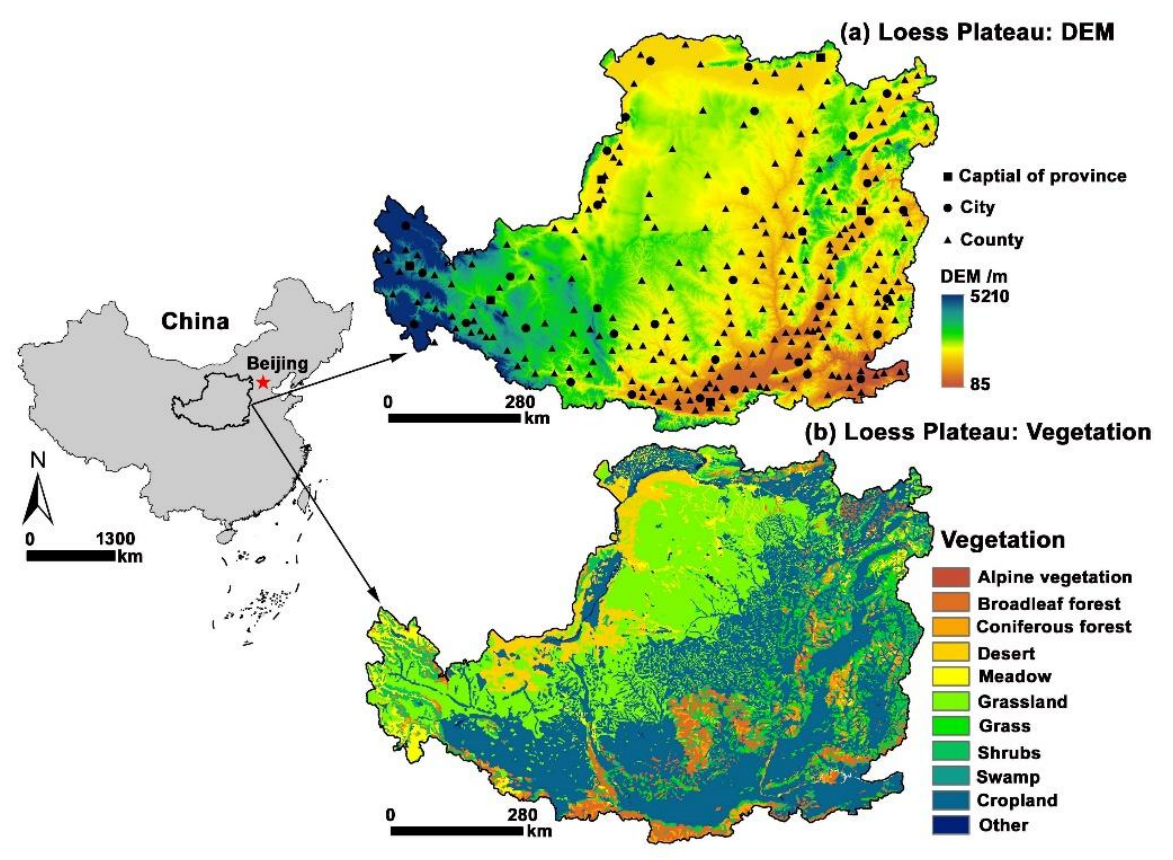

Figure 1. Digital elevation model and vegetation type distribution in the Loess Plateau

Loess is an Aeolian product with a loose texture and strong erodibility. In summer, concentrated precipitation and complex terrain are the important factors influencing soil water erosion in the middle and eastern parts, while the northwestern part of the plateau experiences severe soil wind erosion. Vegetation and water distribution are closely related and have a southeast-northwest distribution, mainly including coniferous forests, broadleaf forests, shrub lands, deserts, grasslands grass, meadows, swamps, alpine vegetation and cropland (CVEB of CAS, 2001) (Fig. 1b). The Loess Plateau is located 
in the middle of the Yellow River basin. The rivers in the territory include the Huangshui, Qingshui, Kuye, Wuding, Yanhe, Beiluo, Jinghe, Weihe and Fenhe Rivers. The Loess Plateau has a long history of development and is one of the more densely populated areas in China, which means that the original vegetation on the surface has been greatly damaged and reclaimed for cultivated lands. China's reform and opening up, rapid economic development led to a heavy urban expansion in the region. In addition, climate change, especially temperature rise and increased frequency of extreme precipitation, has caused changes in the surface vegetation in the area, while GGP has also impacted land use and land cover in the Loess Plateau. Scientific analysis of this process can provide a basis for the adjustment and restriction of human activities within the Loess Plateau.

\section{Data}

The data used in this study included: (1) land use raster data for China with a spatial resolution of $1 \mathrm{~km}$ in 1980, 1990, 2000 and 2015, in which land use was divided into six types: cultivated land, forest land, grassland, water body, construction land and unutilized land. (2) China's annual average temperature and precipitation raster data had a spatial resolution of $1 \mathrm{~km}$ from 1980 to 2015 . The data was generated by interpolating daily observation data from more than 2400 weather stations throughout the country using ANUSPLINE software. (3) An SRTM (Shuttle Radar Topography Mission) digital elevation model (DEM) had a spatial resolution of $90 \mathrm{~m}$. (4) Vector boundaries of the Loess Plateau and point data for provincial capitals, cities and counties were also included. These datasets were provided by Data Center for Resources and Environmental Sciences, Chinese Academy of Sciences (RESDC) (http://www.resdc.cn). (5) Third generation Global Inventory Monitoring and Modelling System NDVI from Advanced Very High-Resolution Radiometer sensors (GIMMS AVHRR NDVI3g) data from 1982 to 2015 with a spatial resolution of $0.05^{\circ}$ were downloaded from http://ecocast.arc.nasa.gov/data/pub/gimms/3g.v1/.

Data from (1), (2) and (5) above were used to obtain land use, temperature and precipitation; and NDVI in the Loess Plateau was extracted in ArcGIS software based on the vector boundaries. The NDVI and DEM data were resampled to $1 \mathrm{~km}$ resolution.

\section{Methods}

\section{Single factor analysis}

(1) Vegetation NDVI trends and $F$ test

The trend analysis used a linear regression model to analyze the temporal and spatial change process and the possible future change direction of NDVI in the Loess Plateau, as well as to reflect the linear change trend and spatial distribution in the study period. It is calculated as follows $(\mathrm{Xu}, 2014)$ :

$$
\begin{gathered}
Y=a X+b \\
a=\frac{\sum_{i=1}^{n} x_{i} y_{i}-n \bar{x} \bar{y}}{\sum_{i=1}^{n} x_{i}^{2}-n \bar{x}^{2}}
\end{gathered}
$$




$$
b=\bar{y}-a \bar{x}
$$

where: $Y$ is the NDVI value or spatial distribution data; $X$ is the year 1982-2015; $a$ is a coefficient; $b$ is a constant; $\bar{x}$ and $\bar{y}$ are the average values of $X$ and $Y$. Positive or negative values of $a$ reflect a linear increase or decrease of vegetation NDVI.

For the linear regression model using the $F$ test for significance, the formula is as follows (Xu, 2014):

$$
F=U /[Q /(n-2)]
$$

where: $Q=\sum_{i=1}^{n}\left(y_{i}-\hat{y}_{i}\right)^{2}, U=\sum_{i=1}^{n}\left(\hat{y}_{i}-\bar{y}\right)^{2} ; \hat{y}$ is the fitted value of y calculated using values for $a, b$ and $x$; and the other parameters are the same as in the previous formula. In an $F$ test threshold table, when $\alpha=0.05$, the critical value is 4.15 . This means that a linear trend is significant when $F>4.15$, and not significant otherwise.

(2) Impact analysis of climate change on NDVI

The correlation coefficient was used to identify the relationship between climate change and vegetation change, and the formula is as follows (Xu, 2014):

$$
r=\frac{\sum_{i=1}^{n}\left(x_{i}-\bar{x}\right)\left(y_{i}-\bar{y}\right)}{\sqrt{\sum_{i=1}^{n}\left(x_{i}-\bar{x}\right)^{2}} \sqrt{\sum_{i=1}^{n}\left(y_{i}-\bar{y}\right)^{2}}}
$$

where: $x$ and $y$ are NDVI and temperature and precipitation, respectively. The $r$ value ranges between $[-1,1]$, where $r=0$ means that the two variables are irrelevant. The closer the value of $r$ is to -1 , the stronger the negative correlation. The closer it is to 1 , the stronger the positive correlation. In the correlation coefficient threshold table, when $\alpha=0.05$, the critical value of $\mathrm{r}$ is 0.3494 . That is, a correlation coefficient value of $|r|>0.3494$ is significant, and not significant otherwise.

(3) Impact analysis of urban expansion on LUCC

The impacts of urban expansion on LUCC were mainly concentrated in areas near cities and decreased with distance from cities. A buffer analysis method was used to generate a $30 \mathrm{~km}$ buffer around the provincial capitals and cities at intervals of $2 \mathrm{~km}$. Counties adopted $1 \mathrm{~km}$ intervals within $10 \mathrm{~km}$ and $2 \mathrm{~km}$ intervals in the range of $10 \mathrm{~km}$ to $20 \mathrm{~km}$. The average NDVI values and changes were analyzed within the buffer zones from 1982 to 2015. The limits of urban expansion affecting vegetation were identified, and that boundary was used as the criterion for the impact of urban expansion on LUCC process, after which the relative change rate of land use within and outside the boundary was calculated. The formula is as follows:

$$
\begin{gathered}
\text { Area_avg } g_{b l c t}=\frac{A_{b l c t}}{\operatorname{Urban}_{n c}} \\
R C=\left(\frac{\text { Areaavg }_{b l c(t+1)}}{\text { SArea }_{b(t+1)}}-\frac{\text { Area_avg }_{b l c t}}{S A r e a_{b t}}\right) \times 100 \%
\end{gathered}
$$


where: $R C$ is the relative change rate, \%; Area_avg $g_{b l c t}$ and Area_avg $g_{b l c(t+1)}$ represent the average area of $l$ land use type within buffer $b$ of city $c$ (or provincial capital/county) at time $t$ and $t+1$, respectively, $\mathrm{km}^{2} ; S_{\text {Area }} a_{b t}$ denotes the total area of all land use types in buffer $b$ at time $t, \mathrm{~km}^{2} ; A_{\text {blct }}$ represents the area of $l$ land use type in buffer $b$ of city $c$ (or provincial capital/county) at time $t, \mathrm{~km}^{2} ; \operatorname{Urban}_{n c}$ represents the number of city $c$ (or provincial capital/county).

(4) Impact analysis of GGP on LUCC

The implementation of GGP was mainly aimed at areas with slope $>=25^{\circ}$, and the influence on LUCC as also considered to be mainly distributed in the area of $>=25^{\circ}$. Statistics on land use and NDVI changes in the region of $>=25^{\circ}$ in the Loess Plateau before and after 2000 were used to determine the impact of GGP on LUCC. Land use statistics were calculated using the change rate method:

$$
\begin{gathered}
R_{t s l}=\frac{\operatorname{Area}_{t s l}}{\operatorname{SumA}_{t l}} \times 100 \% \\
C R=R_{(t+1) s l}-R_{t s l}
\end{gathered}
$$

where: $C R$ is the change rate, $\% ; R_{t s l}$ and $R_{(t+1) s l}$ represent the percentage of land use type $l$ on slope $s$ at time $t$ and $t+1$, respectively, \%; Area $a_{t s l}$ denotes the area of land use type $l$ on slope $s$ at time $t, \mathrm{~km}^{2} ; \operatorname{SumA}_{t l}$ denotes the area of land use type $l$ at time $t, \mathrm{~km}^{2}$.

\section{Comprehensive factor analysis}

Based on the single factor analysis above, the change in LUCC in the Loess Plateau from 1980 to 2015 and the impacts of climate change, urban expansion, and the implementation of GGP on LUCC were obtained. However, it was still necessary to quantitatively determine the role of each factor in the LUCC process and their spatial distributions through comprehensive mapping of multiple influencing factors. This analysis involved land use, $F$ test results for the NDVI change process, and correlation coefficients between NDVI and temperature and precipitation. It also involved analysis results for the impact of urban expansion and the implementation of GGP. The calculated method was as follows:

(1) Land use $(L D)$ : Based on the land use classification of the Loess Plateau in 2015, the values of construction land, cultivated land, and water body were assigned to 4, 3, 1, respectively, and the values of forest land, grassland, and unutilized land were assigned to 2 .

(2) $F$ test results of the NDVI change process $(F T)$ : The values for significant and not significant decreases were assigned to 4 and 3, respectively, and the respective values for not significant and significant increases were assigned to 2 and 1.

(3) Correlation coefficients between NDVI and temperature $(T E)$ and precipitation $(P E)$ : The values for significant and not significant negative correlation were assigned to 4 and 3 , respectively, and positive and significant positive correlation values were assigned to 2 and 1 , respectively.

(4) The impact of urban expansion $(U P)$ : Within the range of urban expansion for the provincial capitals, cities, and counties in 2015, the value of construction land was assigned to 4, farmland, forest land, grassland, water body and unutilized land were assigned to 3 , and values outside the range were assigned to 2 . 
(5) The impact of GGP (IGGP): The value of construction land in the region with slope $>=25^{\circ}$ in 2015 was assigned to 4 . The value of cultivated land converted into forest land and grassland between 2000 and 2015 was assigned to 3. The value of cultivated land in the region with slope $>=25^{\circ}$ in 2015 was assigned to 2 . All other values were assigned to 1 .

(6) Comprehensive evaluation results: The formula was as follows:

$$
C E=L D \times 100000+F T \times 10000+T E \times 1000+P E \times 100+U P \times 10+I G G P \quad(\text { Eq.10) }
$$

where:

$C E$ is the comprehensive evaluation of the results.

$C E$ ranged between 111111 and 444444 and was composed of six digits. From left to right, the first digit indicated land use, the second indicated the $F$ test result for NDVI change, the third indicated the correlation between NDVI and temperature, the fourth indicated the correlation between NDVI and precipitation, the fifth indicated urban expansion, and the sixth indicated GGP. The larger the value of $C E$, the greater the impact of urban expansion was, while the smaller the value, the less affected the area was by human activities and the greater the impact of climate change was.

The specific classification method was as follows, according to the area statistics for each type and spatial mapping:

(1) If the six digits of the CE contained the number 4, it was divided into the area impacted by urban expansion.

(2) If the six digits of the CE contained the number 1 but did not contain the number 4 , and the 6 th number was not 3 , it was divided into the area impacted by climate change.

(3) If the 6th digit of the CE was 3, it was divided into the area impacted by GGP implementation.

(4) The parts not assigned to the above areas were divided into the area impacted by other factors.

\section{Results}

\section{The LUCC process in the Loess Plateau}

\section{Land use change process}

The statistics for land use in the Loess Plateau showed that (Table 1) the land use structure generally remained stable with grassland, cultivated land, and forest land dominating between 1980 and 2015 and accounting for $41.80 \%, 32.34 \%$, and $15.02 \%$ of the total area, respectively. However, grassland and cultivated land decreased by $0.57 \%$ and $0.59 \%$, respectively, while forest land increased by $0.41 \%$ over the study period. In addition, the largest increase was in construction land at $1.08 \%$.

The amount and rate of land use change were different at different periods. Between 1980 and 2015, the area of cultivated land, grassland, water body, and unutilized land decreased greatly, while the area of forest land and construction land increased greatly. Due to the large area of the Loess Plateau, although the area changed was large, it made up a relatively small proportion of the total area. The decrease in grassland was the largest at $5.45 \%$, and the increase in construction land was the highest at $51.54 \%$. Between 1980 and 2000, the area of forest land, grassland, water body, and unutilized 
land decreased, and the area of cultivated land and construction land increased. During this period the decrease in water body was the largest at $9.00 \%$, and the increase in construction land was highest at $11.97 \%$. Between 2000 and 2015, the area of farmland, grassland, and unutilized land decreased greatly, while the area of forest land, water body and construction land greatly increased. During this period, the decrease in the cultivated land was the largest at $2.74 \%$, and the increase in construction land was the highest at $35.34 \%$.

Table 1. Area and change rate of land use type between 1980 and 2015

\begin{tabular}{|c|c|c|c|c|c|c|c|}
\hline Type & Year & Farmland & Forest land & Grassland & Waterbody & $\begin{array}{c}\text { Construction } \\
\text { land }\end{array}$ & $\begin{array}{c}\text { Unutilized } \\
\text { land }\end{array}$ \\
\hline \multirow{4}{*}{$\begin{array}{c}\text { Area }\left(\mathrm{km}^{2}\right) / \\
\text { percentage }(\%)\end{array}$} & & & 94959 & $4254 / 41.80$ & & $13229 / 2.09$ & $44562 / 7.05$ \\
\hline & 1990 & $206544 / 32.68$ & $94776 / 14.99$ & $263861 / 41.74$ & $8904 / 1.41$ & $13558 / 2.14$ & $44452 / 7.03$ \\
\hline & 2000 & $207497 / 32.82$ & $94909 / 15.01$ & $262452 / 41.51$ & $8843 / 1.40$ & $14812 / 2.34$ & $43735 / 6.92$ \\
\hline & 2015 & $201820 / 31.92$ & $97535 / 15.43$ & $260661 / 41.23$ & $9188 / 1.45$ & $20047 / 3.17$ & $42998 / 6.80$ \\
\hline \multirow{3}{*}{$\begin{array}{l}\text { Amount }\left(\mathrm{km}^{2}\right) \\
\text { and rate }(\%) \text { of } \\
\text { change }\end{array}$} & م & $1967 / 0.96$ & $-50 /-0.05$ & $-1802 /-0.68$ & $-875 /-9.00$ & $1583 / 11.97$ & $-827 /-1.86$ \\
\hline & $2000-2015$ & $-5677 /-2.74$ & $2626 / 2.77$ & $-1791 /-0.68$ & $345 / 3.90$ & $5235 / 35.34$ & $-737 /-1.69$ \\
\hline & $1980-2015$ & $-3710 /-1.81$ & $2576 / 2.71$ & $-3593 /-1.36$ & $-530 /-5.45$ & $6818 / 51.54$ & $-1564 /-3.51$ \\
\hline \multirow{3}{*}{$\begin{array}{c}\text { Amount } \\
\left(\mathrm{km}^{2} / \mathrm{a}\right) \text { and } \\
\text { rate }(\% / \mathrm{a}) \text { of } \\
\text { annual change }\end{array}$} & $1980-2000$ & $98.4 / 0.05$ & $-2.5 /-0.003$ & $-90.1 /-0.03$ & $-43.8 /-0.45$ & $79.2 / 0.60$ & $-41.4 /-0.09$ \\
\hline & $2000-2015$ & $-378.5 /-0.18$ & $175.1 / 0.18$ & $-119.4 /-0.05$ & $23.0 / 0.26$ & $349.0 / 2.36$ & $-49.1 /-0.11$ \\
\hline & $1980-2015$ & $-106.0 /-0.05$ & 73.6/0.08 & $-102.7 /-0.04$ & $-15.1 /-0.16$ & $194.8 / 1.47$ & $-44.7 /-0.10$ \\
\hline
\end{tabular}

Between 1980 and 2015, the annual reduction in cultivated land and grassland was the largest, with the largest increase in construction land. The rate of annual change in grassland was the largest decrease and change in construction land was the largest increase. Between 1980 and 2000, the annual increase in cultivated land and construction land was the largest, and the annual decrease in grassland and the unutilized land was the largest. The largest decrease in the rate of annual change was in the waterbody, and the largest increase in the rate of annual change was in construction land. Between 2000 and 2015, the annual reduction in farmland was the largest, and the largest increase was in construction land. The rate of annual change in the cultivated land was the largest decrease, and the largest increase was in construction land during 2000-2015.

The above analysis showed that the land use structure of the Loess Plateau was stable between 1980 and 2015, but overall the area of cultivated land and grassland decreased, and the area of construction land and forest land increased. The area of farmland increased prior to 2000 and decreased after 2000, and the decrease was 2.89 times greater than the increase. The area of forest land change was opposite than that of farmland, where the area of increase was 52.52 times the area of decrease. Grassland area continued to decrease, and construction land continued to increase during 19802000 and 2000-2015. The change in farmland and forest land was clearly impacted by the implementation of GGP. The increase in construction land was affected by urban expansion caused by rapid social and economic development in the region. As the area of grassland continued to decrease, it may have been related to cultivated land occupied prior to 2000. However, the subsequent reduction was not consistent with the area increase caused by GGP implementation. 


$$
-4153-
$$

\section{NDVI change process}

Equations 1, 2, 3, and 4 were used to obtain the spatial and temporal change rate of NDVI and $F$ test results (Fig. 2). From 1982 to 2015, the NDVI in the Loess Plateau increased significantly and $\left(y=0.002 x-3.824, R^{2}=0.653, P<0.001\right)$ with a linear growth rate of 0.02/10a. However, it could be divided into two stages: before and after 2000. Both stages showed a significant linear increase; however, the growth rate of the first stage was slower $\left(y=0.001 x-1.797, R^{2}=0.246, P<0.05\right)$, and the linear growth rate was $0.01 / 10 \mathrm{a}$. In the latter stage, the growth rate was faster $(y=0.005 x-10.359$, $R^{2}=0.840, P<0.001$ ), and the linear growth rate was $0.05 / 10 \mathrm{a}$, which was five times the growth rate of the previous stage (Fig. 2a).
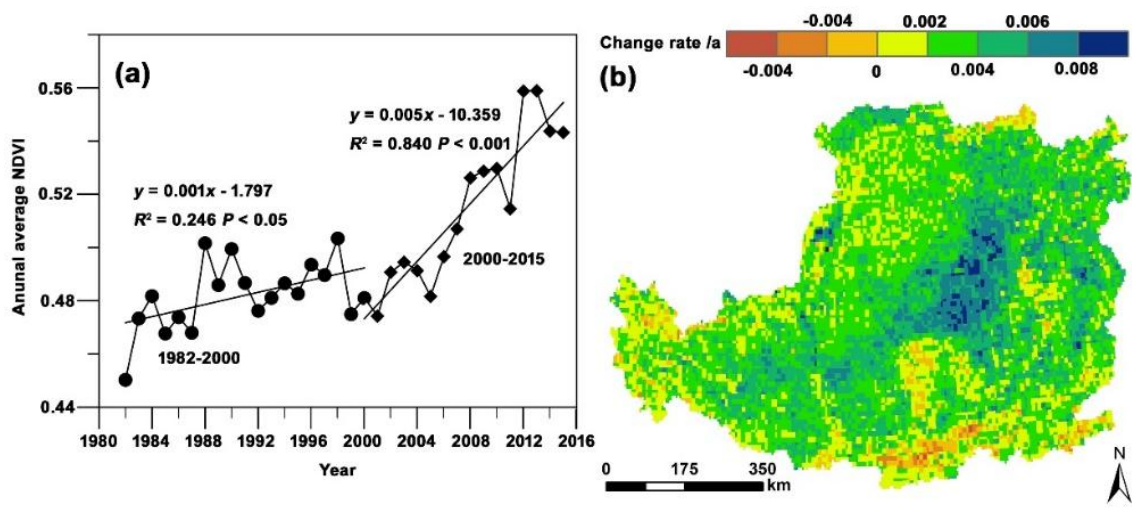

(c)

(d)

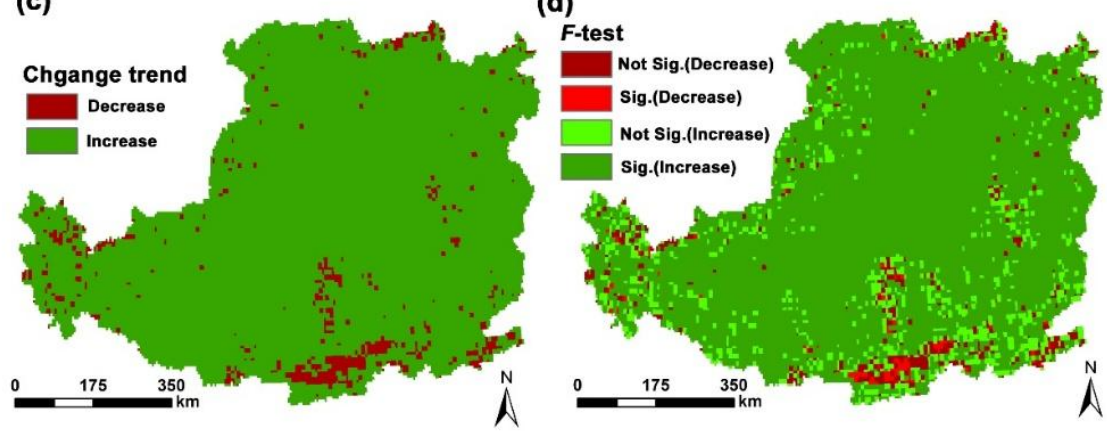

Figure 2. Spatial and temporal distribution of NDVI change. (a) Temporal change process; $(b)$ change rate; $(c)$ change trend; $(d) F$ test results of change trend

The linear change rate and change trend of NDVI indicated that (Fig. $2 b$ and $c$ ): the linear growth trend in the Loess Plateau from 1982 to 2015 accounted for $94.86 \%$, while the decreasing trend only accounted for $5.14 \%$. In the growth trend, the change rate was mostly concentrated between $0-0.006 / \mathrm{a}$, accounting for $87.51 \%$, of which $0.002-0.004 / a$ accounted for $40.68 \%$. The spatial growth rate and trend were widely distributed, the growth rate was greater with the land closer to the centre part of the Loess Plateau, while smaller with the land farther from the centre. Where the trend was decreasing, the areas with negative change rates were mainly located in the marginal zone, especially in the southern part of the study area, and the distribution around the western, northern and eastern areas was scattered.

The $F$ test results for NDVI change indicated that (Fig. $2 d$ ), there was significant growth in the Loess Plateau from 1982 to 2015 that accounted for $83.82 \%$ of the total 
area, while not significant growth accounted for $11.04 \%$, and was mainly in the marginal areas of the Loess Plateau. Areas with significant and not significant reduction trend distributions were small, accounting for only $0.93 \%$ and $4.21 \%$, respectively, and were concentrated in the southern area, scattered around the eastern, western, and northern margins of the region.

The above analysis indicated that the NDVI of the Loess Plateau generally increased linearly from 1982 to 2015 , during which time the NDVI growth rate after 2000 was affected by the implementation of GGP and was five times faster than before 2000. The NDVI of the Loess Plateau was dominated by a significant growth trend. The closer to the middle of the region, the higher the growth rate, and vice versa. The decreased trend was concentrated in the southern part of the region, scattered around the eastern, western, and northern margins.

\section{The impact of climate change on NDVI}

The LUCC process is made up of two parts: land use and land cover change. The former is mainly affected by human activities and reflects the macroeconomic pattern of human activities. The latter is affected not only by human activities but also by climate change. Human activities affect land cover by changing the land use, while climate change changes the hydrothermal conditions to affect the distribution of surface vegetation. The land cover change in this paper was represented by NDVI.

From 1961 to 2014, the temperature in the Loess Plateau increased, while the precipitation fluctuate decreased (Yan, 2015), and the frequency of precipitation intensity and extreme precipitation increased (Wang et al., 2014a, b). Equation 5 was used to obtain the correlation between NDVI and both temperature and precipitation (Fig. 3). It shows that there were clear correlations between NDVI and annual temperature and precipitation in the Loess Plateau from 1982 to 2015 (Fig. 3). The correlation between NDVI and annual temperature was positive, accounting for $82.22 \%$ of the total, with a significant positive correlation area accounting for $25.91 \%$ of that and a significant negative correlation area accounting for only $1.77 \%$. The positive and significant positive correlation distribution was consistent with the change trend (Fig. 2c), and mainly distributed in the centre of the region. The significant positive correlations were found in the centre and northern parts of the region and in the southern part of the region from west to east. The negative and significantly negative correlations were concentrated in the southern, western, and southwestern parts of the region.

From 1982 to 2015, the positive and significantly positive correlations between NDVI and precipitation accounted for $84.84 \%$, and the significantly positive correlation area accounted for $23.63 \%$, while the significant negative correlation area accounted for only $0.44 \%$. In terms of spatial distribution, positive and significantly positive correlations were concentrated in a large area of the centre region. Significantly positive correlations were mainly located in the north, northwest, and southwest, while negative correlations were mainly distributed in the southeast, southwest, and northwest, as well as the centre regions with a scattered distribution.

The above analysis indicated that vegetation changes in most parts of the Loess Plateau from 1982 to 2015 were affected by temperature and precipitation, and the correlations with temperature and precipitation were mainly positive, in which significantly positive correlations were greater than $20 \%$. It showed that climate change had the dominant effect on vegetation change in the Loess Plateau. However, human 


$$
-4155-
$$

activities in the Loess Plateau were intense, and the changes in vegetation in some areas were completely dominated by human activities.

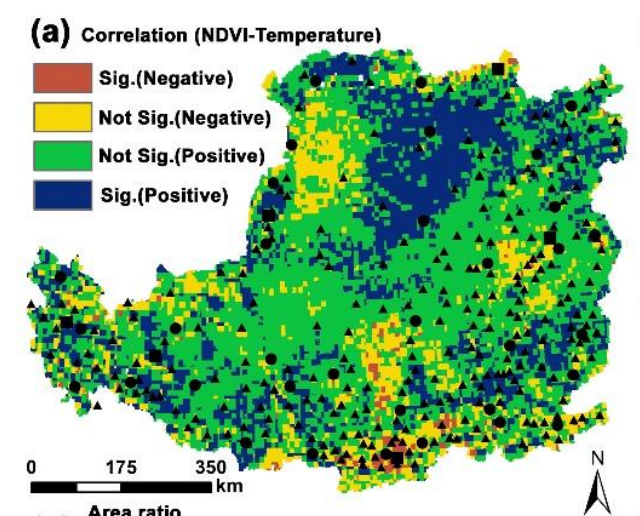

(b) Correlation (NDVI-Precipitation)
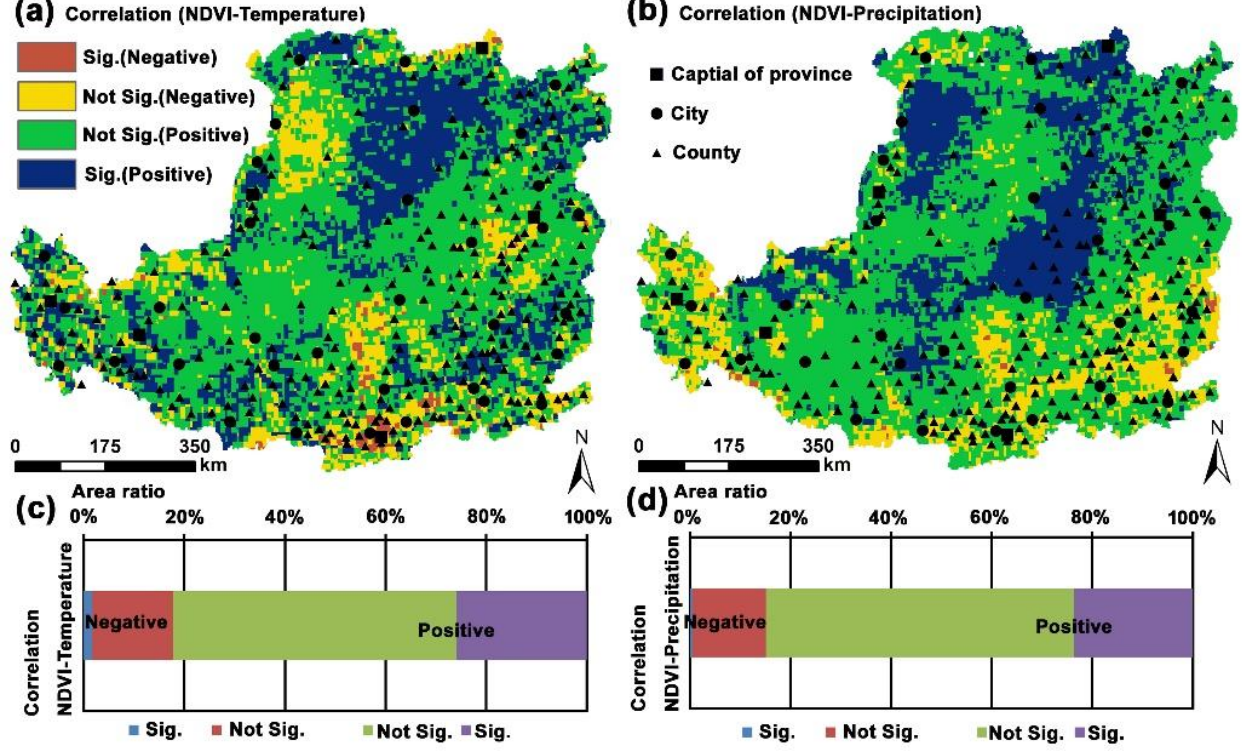

Figure 3. Distribution of correlations and area ratios between NDVI and temperature and precipitation. (a) Correlation between NDVI and temperature; (b) correlation between NDVI and precipitation; (c) statistical results of correlation between NDVI and temperature; (d) statistical results of correlation between NDVI and precipitation

\section{The impact of urban expansion on LUCC}

The impact of urban expansion on LUCC process was analyzed from two aspects, namely the process of NDVI change and the process of land use change. The average NDVI from 1982 to 2015 in different buffer zones was calculated in provincial capitals, cities and counties, respectively (Fig. $4 a, c$ and $e$ ). By determining the buffer distance corresponding to the inflection point of the average NDVI value, the relative change rates for land use types between 1982-2015 before and after the inflection point were calculated according to Equations 6 and 7 (Fig. 4b, d, and f).

Urban expansion was one of the most important characteristics of the current LUCC process. Because the administrative level of the city directly affects urban expansion, the cities of the Loess Plateau were divided into three categories: provincial capitals, cities, and counties.

Within the $30 \mathrm{~km}$ buffer zone of the provincial capitals, the inflection point for average NDVI change occurred at $18 \mathrm{~km}$. NDVI had rapid and significant linear growth before the inflection point and stabilized after the inflection point (Fig. 4a). From 1982 to 2015 , there were clear differences in land use change within the $18 \mathrm{~km}$ and $18-30 \mathrm{~km}$ buffer zones of the provincial capitals. For the former, the decrease in farmland and the increase in construction land were higher than those in the latter by 9.9 and 3.6 times, respectively (Fig. 4b). $18 \mathrm{~km}$ can, therefore, be used as the urban expansion boundary for provincial capitals in the Loess Plateau.

Within the $30 \mathrm{~km}$ buffer zone, the average NDVI inflection point occurred at $14 \mathrm{~km}$, and the buffer was divided into $0-14 \mathrm{~km}$ and $14-30 \mathrm{~km}$. The average NDVI value had a 


$$
-4156-
$$

significant linear increase, but the linear growth of the former is 5.6 times than the latter (Fig. 4c). From 1982 to 2015, land use in the $14 \mathrm{~km}$ and 14-30 km buffer zones of cities also had clear differences, where cultivated land was reduced, and construction land increased in the former by 3.6 times, and the same value was only 2.7 times in the latter (Fig. 4d). This demonstrated that $14 \mathrm{~km}$ could be used as the urban expansion boundary of cities in the Loess Plateau.
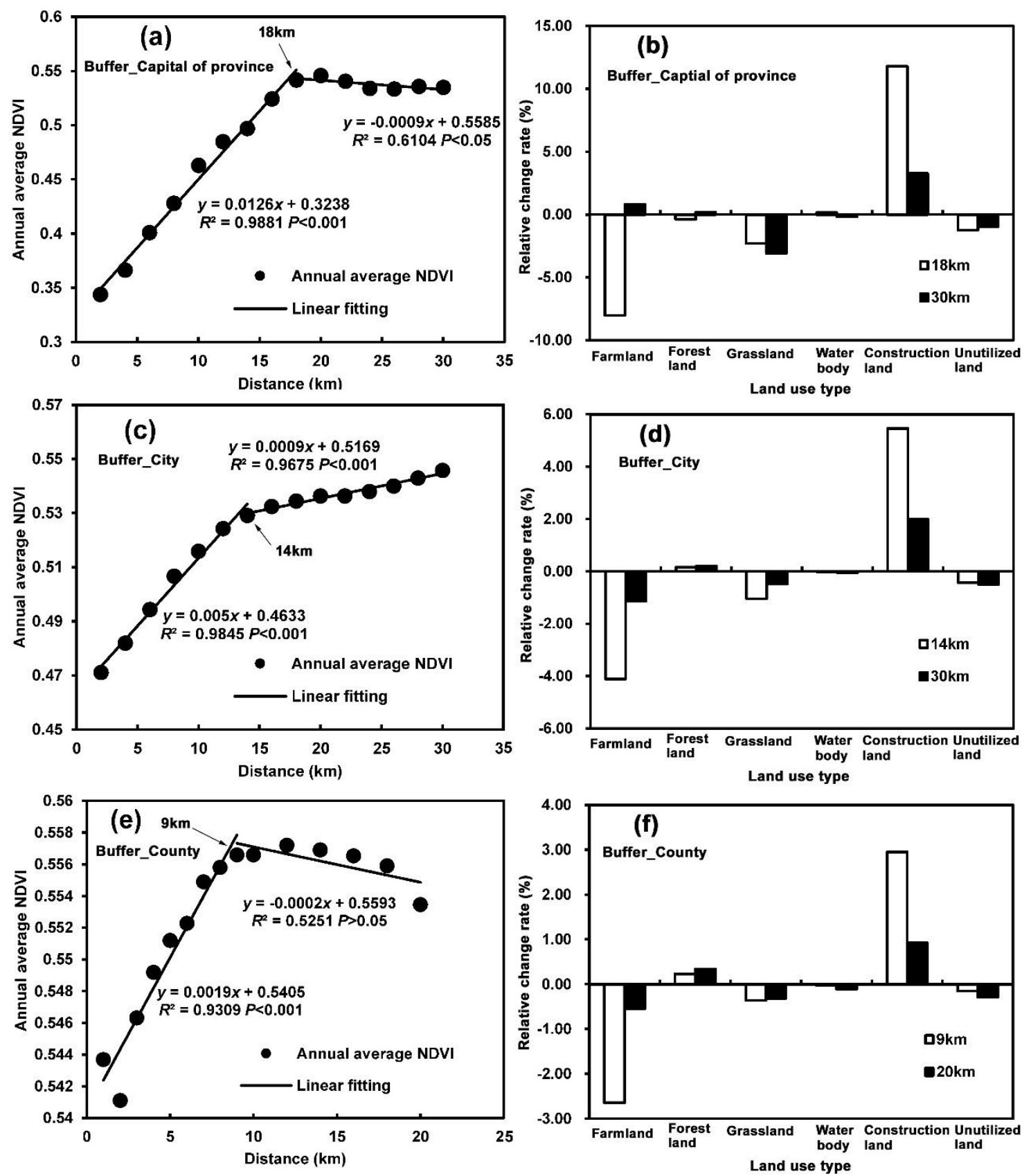

Figure 4. Annual average NDVI changes (1982-2015) and land use change ratios (1980-2015) for different administrative buffers. (a) Average NDVI change in provincial capitals from 1982

to 2015; (b) relative change rate in land use in provincial capitals from 1980 to 2015; (c) average NDVI change in cities from 1982 to 2015; (d) relative change rate of land use in cities from 1980 to 2015; (e) average NDVI change in counties capitals from 1982 to 2015; (f) relative change rates of land use in counties from 1980 to 2015 
Within the $20 \mathrm{~km}$ buffer zone, the NDVI inflection point appeared at $9 \mathrm{~km}$. Prior to that, there was a significant linear NDVI growth, and the change rate in the 0-9 $\mathrm{km}$ buffer was higher than in 9-30 km (Fig. 4e). From 1982 to 2015, there was an obvious difference in land use between $9 \mathrm{~km}$ and $9-30 \mathrm{~km}$ buffer zone in counties, where farmland decreased, and construction increased in the former by 4.8 times and increased 3.2 times in the latter (Fig. $4 f$ ). That indicated that $9 \mathrm{~km}$ could be used as the urban expansion boundary of counties in the Loess Plateau.

The above analysis indicated that the urban expansion boundaries for provincial capitals, cities, and counties in the Loess Plateau were $18 \mathrm{~km}, 14 \mathrm{~km}$ and $9 \mathrm{~km}$, respectively. Within the boundaries, the rapid reduction of cultivated land and the rapid increase of construction land were observed, while outside the boundary the reduction in cultivated land and the increase in construction land were far below the limit.

\section{The impact of GGP on LUCC}

Due to its fragile environment, the Loess Plateau is a key region for the implementation of the GGP, which focused on areas with slope $>=25^{\circ}$. The percentage of each land use type across the total region, annual average NDVI values for the Loess Plateau from 1980 (1982) to 2015, and accompanying statistics are calculated according to Equations 8 and 9 (Fig. 5).

Taking the time of GGP implementation as the dividing point, the study period was divided into 1980 (1982)-2000 and 2000-2015. Between 1980 and 2015, the proportion of cultivated land to total cultivated land in the Loess Plateau $>=25^{\circ}$ increased slightly, and the proportion of forest land and construction land decreased, while grassland increased (Fig. 5a). Correspondingly, the annual average NDVI value in the area $>=25^{\circ}$ from 1982 to 2015 , was generally higher than the area $<25^{\circ}$; however, the linear increase in the area $>=25^{\circ}$ was not significant, while the linear increase in the area $<25^{\circ}$ was significant (Fig. 5b). This indicated that the higher slopes limited human activities and maintained better vegetation conditions, while lower slope vegetation was also improved. Between 2000 and 2015, the GGP was implemented, and the proportion of cultivated land $>=25^{\circ}$ of the Loess Plateau decreased (Fig. 5c). The NDVI in $>=25^{\circ}$ also showed a faster increase from 2000 to 2015 than from 1982 to 2015; moreover, and the linear growth rate also exceeded the area of $<25^{\circ}$ (Fig. 5d). This showed that the implementation of the GGP greatly promoted the improvement of vegetation in the higher gradient.

Between 1980 and 2000, on the whole, the proportion of farmland decreased, and the proportion of grassland increased in the area of $>=25^{\circ}$ (Fig. 5e). At the same time, both areas of slope $>=25^{\circ}$ and slope $<25^{\circ}$ had a significant linear increase in annual NDVI from 1982 to 2015 , and the linear growth rate was similar. However, the linear growth rate in the area of $>=25^{\circ}$ was higher than that of $<25^{\circ}$, which directly reflected the process of land use and land cover change in high slope areas driven by policy (Fig. 5f).

\section{Quantitative assessment of LUCC process driving factors}

According to Equation 10, the impacts of climate change, urban expansion, and GGP implementation on LUCC was assessed quantitatively using comprehensive methods in the Loess Plateau between 1980 and 2015, based on the results of land use change, $F$ test results for NDVI change trends, and the correlations between NDVI and 


$$
-4158-
$$

temperature and precipitation, as well as urban expansion and GGP implementation (Fig. 6).

It indicated that among the influencing factors of LUCC, climate change was the main factor and accounted for 93.65\%, followed by urban expansion (accounting for $5.46 \%$ ), and the implementation of GGP (accounting for $0.64 \%$ ) in the Loess Plateau between 1980 and 2015 (Fig. 6). The role of climate change on the LUCC process was characterized by a wide range of impacts, and areas that could not be covered by human activities, and agricultural production activities, which were still controlled by climate factors. The impacts of climate change on LUCC process had surface-like characteristics.
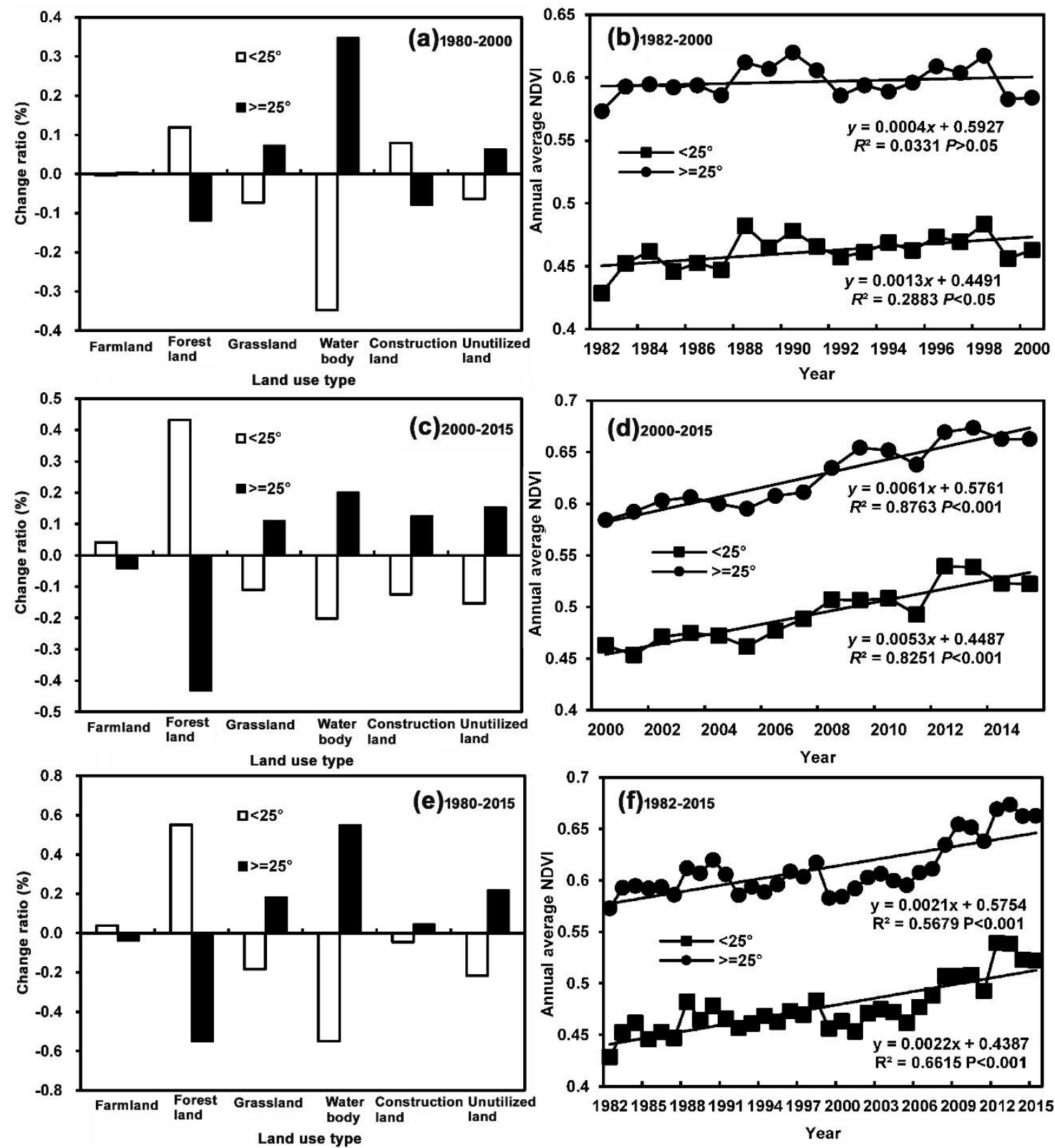

Figure 5. The change process of land use and NDVI in different slop area. (a) land use change between 1980 and 2000; (b) NDVI change from 1982 to 2000; (c) land use change between 2000 to 2015; (d) NDVI change from 2000 to 2015; (e) land sue change between 1980 to 2014;

(f) NDVI change from 1982 to 2015 


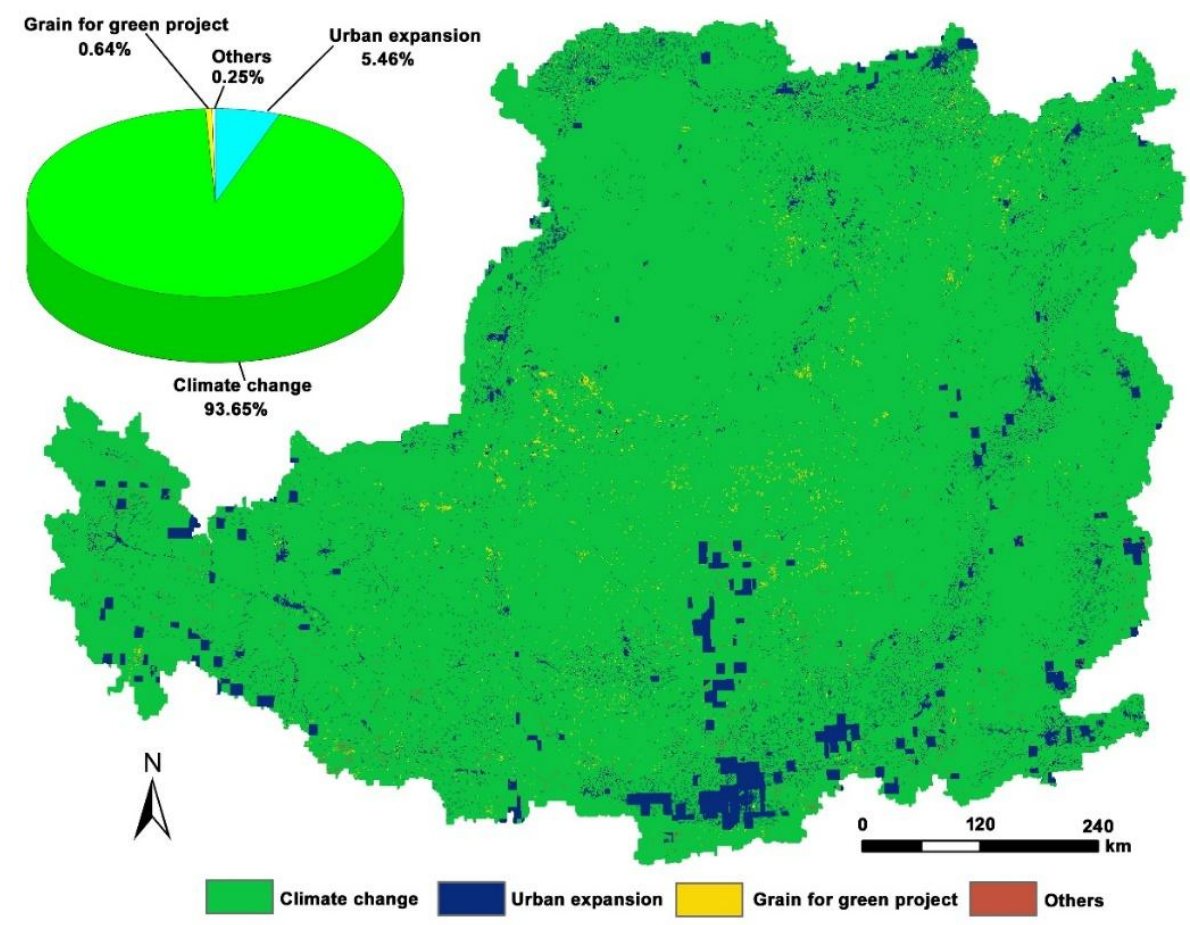

Figure 6. The evaluation results for the impacts of climate change, urban expansion, and the grain for green project on LUCC in the Loess Plateau

Urban expansion was the main driving force for human activities in the LUCC in the Loess Plateau between 1980 and 2015. It reflected the rapid social and economic development and the continued influx of population, and the rapid urbanization process in the Loess Plateau, especially in the southern region where large amounts of farmland, forest land, and grassland, were converted into construction land. The impact of urban expansion on LUCC had point-like characteristics. The impacts of GGP on LUCC were relatively scattered, and related to project implementation and the distribution characteristics in areas with slope $>=25^{\circ}$, and were generally patchy in distribution.

\section{Discussion}

The LUCC process in other countries or regions is mainly affected by urban expansion, deforestation induced by the behavior of farmers, and industrial activities (such as forest development), while the Loess Plateau region of China is unique. Research on the impacts of climate change, urban expansion, and the implementation of GGP on the LUCC process in the Loess Plateau has attracted the attention of many scholars (Theobald, 2005; Chen et al., 2014; Song et al., 2014), but the focus has been on one or two elements, and less on the LUCC process under the combined action of 3 elements. Although quantitative analysis of influencing factors has been carried out, spatial expression was not achieved and maintained half-quantitative methods, which were also the main approach in the current study on the impact of climate change and human activities on the process of natural geographical elements. The research methods and conclusions presented here provide a reference for similar research in other countries or regions. 
The basic framework for quantitative assessment and spatial expression of the impacts of climate change, urban expansion and GGP on LUCC has already been initiated, but some problems remain. The first is data issues, including NDVI and DEM data. The NDVI data used in this paper were GIMMS NDVI from 1982 to 2015, with a spatial resolution of $0.05^{\circ}$ and $1 \mathrm{~km}$ by resampling. However, it is clear that resampling did not solve the problem of low spatial resolution (Fig. 6). The current time-series NDVI data were mainly GIMMS NDVI and SPOT/MODIS NDVI, but the latter time is short. SPOT NDVI and MODIS NDVI started in 1998 and 2000, respectively, and for the study of climate change, the timeframe is slightly shorter. DEM data was at $90 \mathrm{~m}$ resolution and resampled to a $30 \mathrm{~m}$ resolution to extract the slope for the analysis of GGP impacts. However, because the NDVI and land use data were $1 \mathrm{~km}$, it was difficult using the extracted slope for analysis of NDVI and land use. As a whole, quantitative assessment results on the role of GGP implementation were lower, while climate change and urban expansion results were higher.

The second problem was the division of quantitative assessment results. In the article, the analysis method for comprehensive factor was subjective, and the classification of results was too simple, only distinguishing the different functions and spatial distribution, but not distinguishing the spatial distribution of their strengths and weaknesses within the same classification. The third problem was the application of the quantitative assessment results. The Loess Plateau is a typical fragile area in China with serious soil erosion problems, and the vegetation cover is reduced from southeast to northwest, while rapid social and economic development drives large significant urban expansion. Research needs to be conducted on the natural spatial and temporal geographical processes, based on spatial mapping of climate change and human activities (such as urban expansion and GGP).

\section{Conclusion}

Based on a quantitative assessment of the impacts of climate change, urban expansion, and the implementation of GGP on LUCC in the Loess Plateau, the following conclusions were obtained:

(1) The land use structure of the Loess Plateau was stable, and the area of cultivated land and grassland was reduced, while the area of construction land and forestland increased. The area of cultivated land increased prior to 2000 and decreased afterwards, with a decrease that was 2.89 times the increase. Construction land continued to increase. NDVI had an increasing linear trend in general. After 2000, the NDVI growth rate was five times that of the rate before 2000. The significant increasing trend was concentrated in the middle part of the region, and the decrease was concentrated in the south of the region.

(2) The NDVI changes in most parts of the Loess Plateau were positively correlated with changes in air temperature and precipitation, and significant positive correlations were all greater than $20 \%$, which indicated that climate change had a dominant effect on vegetation changes in the Loess Plateau, but changes in vegetation in some areas were completely affected by human activities.

(3) The boundaries of provincial capitals, cities and counties in the Loess Plateau were $18 \mathrm{~km}, 14 \mathrm{~km}$ and $9 \mathrm{~km}$ respectively. The rapid reduction of cultivated land and the rapid increase of construction land were shown within those boundaries. The 


$$
-4161-
$$

reduction in cultivated land and the increase in construction land outside the boundaries were far below the threshold values.

(4) In the area of $>=25^{\circ}$, the proportion of cultivated land decreased, the proportion of grassland increased, and the linear growth rate of NDVI was clearly higher than those areas $<25^{\circ}$, which directly showed that the driving effect was GGP implementation.

(5) Among the influencing factors of LUCC in the Loess Plateau, climate change was dominant, accounting for $93.65 \%$ of the total, with a surface-like distribution. It was followed by urban expansion, accounting for $5.46 \%$ of the total, with a point-like distribution. The impact of GGP accounted for $0.64 \%$ and had a patchy distribution.

Acknowledgements. This work was supported by the National Key Research and Development Program of China (2016YFC0501707), the National Natural Science Foundation of China (41671086, 41501571), and the Open Foundation of State Key Laboratory of Soil Erosion and Dryland Farming of the Loess Plateau (A314021402-1616).

\section{REFERENCES}

[1] Chen, B. X., Zhang, X. Z., Tao, J., Wu, J. S., Wang, J. S., Shi, P. J., Zhang, Y. J., Yu, C. Q. (2014): The impact of climate change and anthropogenic activities on alpine grassland over the Qinghai-Tibet Plateau. - Agricultural and Forest Meteorology 189-190: 11-18.

[2] Chen, H., Marter-Kenyon, J., López-Carr, D., Liang, X. Y. (2015): Land cover and landscape changes in Shaanxi province during China's grain for green program (20002010). - Environmental monitoring and assessment 187(10): 644.

[3] Chen, H., López-Carr, D., Tan, Y., Xi, J., Liang, X. Y. (2016): China's grain for green policy and farm dynamics: simulating household land-use responses. - Regional Environmental Change 16(4): 1147-1159.

[4] Chinese Vegetation Editorial Board, Chinese Academy of Science (CVEB of CAS) (2001): 1:1 000000 Chinese Vegetation Atlas. - Science Press, Beijing.

[5] Chuai, X. W., Huang, X. J., Lu, Q. L., Zhang, M., Zhao, R. Q., Lu, J. Y. (2015): Spatiotemporal changes of built-up land expansion and carbon emissions caused by the Chinese construction industry. - Environment Science \& Technology 49(21): 1302113030.

[6] Deng, L., Liu, G. B., Shangguan, Z. P. (2014): Land-use conversion and changing soil carbon stocks in China's 'Grain-for-Green' Program: a synthesis. - Global Change Biology 20(11): 3544-3556.

[7] Feng, X. M., Cheng, W., Fu, B. J., Lü, Y. H. (2016): The role of climatic and anthropogenic stresses on long-term runoff reduction from the Loess Plateau, China. Science of the Total Environment 571: 688-698.

[8] Guan, X., Huang, J., Yu, H., Lin, R., Zhang, Y. (2015): Role of radioactively forced temperature changes in enhanced semi-arid warming in the cold season over East Asia. Atmospheric Chemistry and Physics 15(23): 13777-13786.

[9] Jiang, C., Wang, F., Zhang, H. Y., Dong, X. L. (2016): Quantifying changes in multiple ecosystem service during 2000-2012 on the Loess Plateau, China, as a result of climate variability and ecological restoration. - Ecological Engineering 97: 258-271.

[10] Li, J. C., Liu, H. X., Liu, Y., Su, Z. Z., Du, Z. Q. (2015a): Land use and land cover change processes in China's eastern Loess Plateau. - Sciences in Cold and Arid Regions 7(6): 722-729.

[11] Li, S., Liang, W., Fu, B. J., Lü, Y. H., Fu, S. Y., Wang, S., Su, H. M. (2016): Vegetation changes in recent large-scale ecological restoration projects and subsequent impact on 
water resources in China's Loess Plateau. - Science of the Total Environment 569-570: $1032-1039$.

[12] Li, X. M., Zhou, W. Q., Ouyang, Z. Y. (2013): Forty years of urban expansion in Beijing: what is the relative importance of physical, socioeconomic, and neighborhood factors? Applied Geography 38: 1-10.

[13] Li, Y. Q., Lu, C. X., Deng, O., Chen, P. P. (2015b): Ecological characteristics of China's key ecological function areas. - Journal of Resources and Ecology 6(6): 427-433.

[14] Liu, F., Yan, H. M., Gu, F. X., Niu, Z. G., Huang, M. (2017): Net primary productivity increased on the Loess Plateau following implementation of the grain to green program. Journal of Resources and Ecology 8(4): 413-421.

[15] Liu, J. Y., Deng, X. Z. (2010): Progress of the research methodologies on the temporal and spatial process of LUCC. - Chinese Science Bulletin 55(14): 1354-1362.

[16] Liu, J. Y., Kuang, W. H., Zhang, Z. X., Xu, X. L., Qin, Y. W., Ning, J., Zhou, W. C., Zhang, S. W., Li, R. D., Yan, C. Z., Wu, S. X., Shi, X. Z., Jiang, N., Yu, D. S., Pan, X. Z., Chi, W. F. (2014a): Spatiotemporal characteristics, patterns, and causes of land-use changes in China since the late 1980s. - Journal of Geographical Science 24(2): 195-210.

[17] Liu, X. F., Zhang, J. S., Zhu, X. F., Pan, Y. Z., Liu, Y. X., Zhang, D. H., Lin, Z. H. (2014b): Spatiotemporal changes in vegetation coverage and its driving factors in the Three-River Headwaters region during 2000-2011. - Journal of Geographical Science 24(2): 288-302.

[18] Lu, J. F., Dong, Z. B., Hu, G. Y., Li, W. J., Luo, W. Y., Tan, M. L. (2016): Land use and land cover change and its driving forces in Maqu County, China in the past 25 years. Sciences in Cold and Arid Regions 8(5): 432-440.

[19] Malhi, Y., Gardner, T. A., Goldsmith, G. R., Silman, M. R., Zelazowski, P. (2014): Tropical forests in the Anthropocene. - Annual Review of Environment and Resources 39: $125-159$.

[20] Milne, E., Aspinall, R. J., Veldkamp, T. A. (2009): Integrated modelling of natural and social systems in land change science. - Landscape Ecology 24(9): 1145-1147.

[21] Niu, R. X., Zhao, X. Y., Liu, J. L., Qin, Y. (2013): Effects of land use/cover change in the desert Oasis system on topsoil carbon and nitrogen (middle Heihe river basin, China). Polish Journal of Ecology 61(1): 45-54.

[22] Seto, K. C., Güneralp, B., Hutyra, L. R. (2012): Global forecasts of urban expansion to 2030 and direct impacts on biodiversity and carbon pools. - Proceedings of the National Academy of Sciences 109(40): 16083-16088.

[23] Song, W., Chen, B. M., Zhang, Y. (2014): Land-use change and socio-economic driving forces of rural settlement in China from 1996 to 2005. - Chinese Geographical Science 24(5): 511-524.

[24] Su, C. H., Fu, B. J. (2013): Evolution of ecosystem services in the Chinese Loess Plateau under climatic and land use changes. - Global and Planetary Change 101: 119-128.

[25] Theobald, D. M. (2005): Landscape patterns of exurban growth in the USA from 1980 to 2020. - Ecology and Society 10(1): 32.

[26] Wang, Y. F., Liu, Y. S., Li, Y. H., Li, T. T. (2016): The Spatio-temporal patterns of urban-rural development transformation in China since 1990. - Habitat International 53: $178-187$.

[27] Wang, S. X., Wang, S. L. (2013): Land use/land cover change and their effects on landscape patterns in the Yanqi basin, Xinjiang (China). - Environmental Monitoring and Assessment 185(12): 9729-9742.

[28] Wang, T., Yu, D. X., Yang, Q. (2014a): Characteristics of spatial-temporal change of precipitation in loess plateau area of northern Shaanxi. - Journal of Water Resources \& Water Engineering 25(6): 24-29. (In Chinese).

[29] Wang, T., Yang, Q., Yu, D. X. (2014b): Analysis of extreme precipitation in loess plateau area of northern Shaanxi Province. - Yunnan Geographic Environment Research 26(4): 7-14 (in Chinese). 
[30] Wei, W., Xie, Y. W., Shi, P. J., Zhou, J. J., Li, C. H. (2017): Spatial temporal analysis of land use change in the Shiyang river basin in arid China, 1986-2015. - Polish Journal of Environmental Studies 26(4): 1789-1796.

[31] Xie, B. N., Jia, X. X., Qin, Z. F., Shen, J., Chang, Q. R. (2016): Vegetation dynamics and climate change on the Loess Plateau China: 1982-2011. - Regional Environmental Change 16(6): 1583-1594.

[32] Xu, J. H. (2014): Quantitative Geography. - Higher Education Press, Beijing.

[33] Yan, L. B. (2015): Characteristics of temperature and precipitation on the loess plateau from 1961 to 2014. - Journal of Earth Environment 6(5): 276-282 (in Chinese). 